Observation Targeting for the Tehachapi Pass and Mid-Columbia Basin: WindSENSE Phase III Project Summary Report

D. Hanley

October 25, 2011 
This document was prepared as an account of work sponsored by an agency of the United States government. Neither the United States government nor Lawrence Livermore National Security, LLC, nor any of their employees makes any warranty, expressed or implied, or assumes any legal liability or responsibility for the accuracy, completeness, or usefulness of any information, apparatus, product, or process disclosed, or represents that its use would not infringe privately owned rights. Reference herein to any specific commercial product, process, or service by trade name, trademark, manufacturer, or otherwise does not necessarily constitute or imply its endorsement, recommendation, or favoring by the United States government or Lawrence Livermore National Security, LLC. The views and opinions of authors expressed herein do not necessarily state or reflect those of the United States government or Lawrence Livermore National Security, LLC, and shall not be used for advertising or product endorsement purposes.

This work performed under the auspices of the U.S. Department of Energy by Lawrence Livermore National Laboratory under Contract DE-AC52-07NA27344. 


\section{Observation Targeting for the Tehachapi Pass and Mid-Columbia Basin: WindSense Phase III Project Summary Report}

Submitted To: Lawrence Livermore National Laboratory Attention: Chandrika Kamath Livermore, CA

Submitted By: AWS Truepower, LLC 463 New Karner Road Albany, NY 12205 Tel: 518-213-0044 Fax: 518-213-0045

10 October 2011
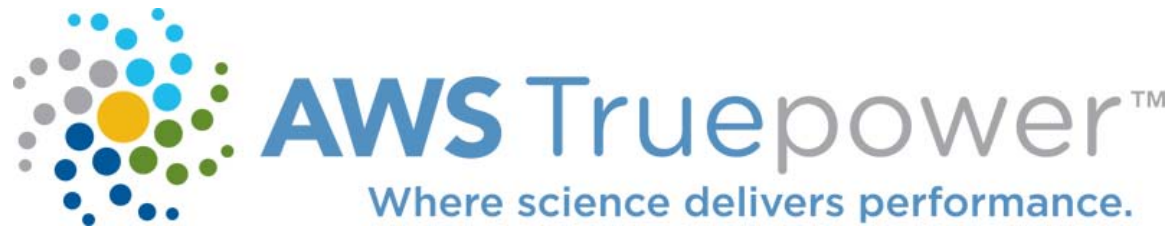


\section{Introduction and Project Objective}

The overall goal of this multi-phased research project known as WindSENSE is to develop an observation system deployment strategy that would improve wind power generation forecasts. The objective of the deployment strategy is to produce the maximum benefit for 1- to 6-hour ahead forecasts of wind speed at hub-height $(\sim 80 \mathrm{~m})$. In Phase III of the project, the focus was on the Mid-Columbia Basin region which encompasses the Bonneville Power Administration (BPA) wind generation area shown in Figure 1 that includes Klondike, Stateline, and Hopkins Ridge wind plants.

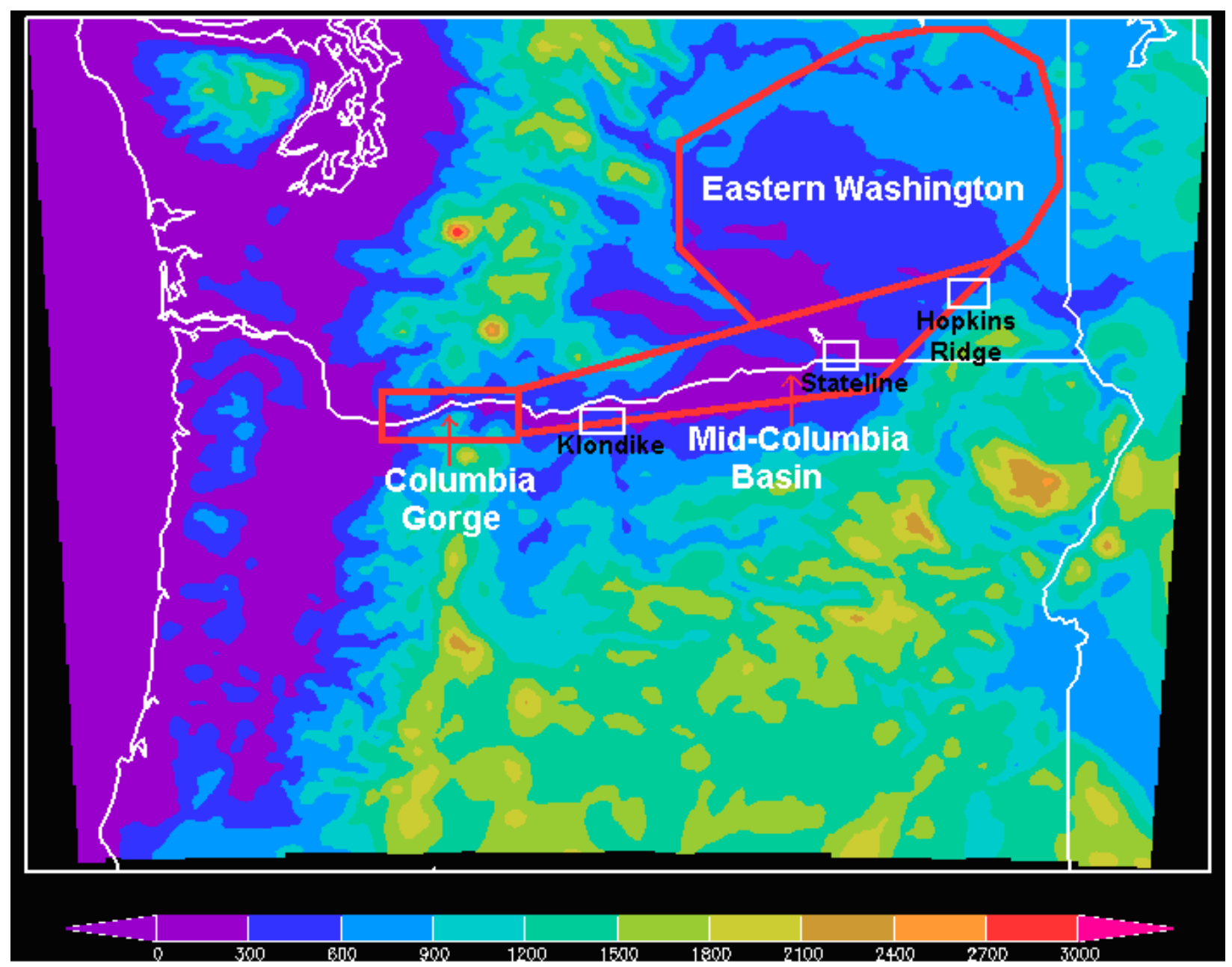

Figure 1. Geographical area used in the ensemble sensitivity analysis experiments. A matrix of 199 by 199 horizontal points with a spacing of approximately $4 \mathrm{~km}$ between points was overlaid on the Washington-Oregon domain for the experiments. The color shading depicts the terrain elevation $(m)$ on the scale of the model grid. The white boxes denote the forecast target areas for which the forecast metric (80-m wind speed) was calculated.

The typical hub height of a wind turbine is approximately $80-\mathrm{m}$ above ground level (AGL). So it would seem that building meteorological towers in the region upwind of a wind generation facility would provide data necessary to improve the short-term forecasts for the 80-m AGL wind speed. However, this additional meteorological information typically does not significantly improve the accuracy of the 0- to 6-hour ahead wind power forecasts because processes controlling wind variability change from day-to-day and, at times, from hour-to-hour. It is also important to note that 
some processes causing significant changes in wind power production function principally in the vertical direction. These processes will not be detected by meteorological towers at off-site locations. For these reasons, it is quite challenging to determine the best type of sensors and deployment locations.

To address the measurement deployment problem, Ensemble Sensitivity Analysis (ESA) was applied in the Phase I portion of the WindSENSE project. The ESA approach was initially designed to produce spatial fields that depict the sensitivity of a forecast metric to a set of prior state variables selected by the user. The best combination of variables and locations to improve the forecast was determined using the Multiple Observation Optimization Algorithm (MOOA) developed in Phase I.

In Zack et al. (2010a), the ESA-MOOA approach was applied and evaluated for the wind plants in the Tehachapi Pass region for a period during the warm season. That research demonstrated that forecast sensitivity derived from the dataset was characterized by well-defined, localized patterns for a number of state variables such as the $80-\mathrm{m}$ wind and the $25-\mathrm{m}$ to $1-\mathrm{km}$ temperature difference prior to the forecast time. The sensitivity patterns produced as part of the Tehachapi Pass study were coherent and consistent with the basic physical processes that drive wind patterns in the Tehachapi area.

In Phase II of the WindSENSE project, the ESA-MOOA approach was extended and applied to the wind plants located in the Mid-Columbia Basin wind generation area of Washington-Oregon during the summer and to the Tehachapi Pass region during the winter. The objective of this study was to identify measurement locations and variables that have the greatest positive impact on the accuracy of wind forecasts in the 0- to 6-hour look-ahead periods for the two regions and to establish a higher level of confidence in ESA-MOOA for mesoscale applications. The detailed methodology and results are provided in separate technical reports listed in the publications section below.

Ideally, the data assimilation scheme used in the Phase III experiments would have been based upon an ensemble Kalman filter (EnKF) that was similar to the ESA method used to diagnose the Mid-Columbia Basin sensitivity patterns in the previous studies. However, running an EnKF system at high resolution is impractical because of the very high computational cost. Thus, it was decided to use a three-dimensional variational (3DVAR) analysis scheme that is less computationally intensive.

The objective of this task is to develop an observation system deployment strategy for the mid Columbia Basin (i.e. the BPA wind generation region) that is designed to produce the maximum benefit for 1- to 6hour ahead forecasts of hub-height $(\sim 80 \mathrm{~m})$ wind speed with a focus on periods of large changes in wind speed. There are two tasks in the current project effort designed to validate the ESA observational system deployment approach in order to move closer to the overall goal:

(1) Perform an Observing System Experiment (OSE) using a data denial approach.

(2) Conduct a set of Observing System Simulation Experiments (OSSE) for the Mid-Columbia basin region.

\section{Summary}

In Phase I, the ESA-MOOA approach was applied to Tehachapi Pass region during the summer season. In Phase II, the ESA-MOOA approach was applied to Mid-Columbia region from 1 May to 19 June 2007 (warm/summer season) and to the Tehachapi Pass region from 1 January to 18 February 2010 (winter/cool season) for a series of 48 ensemble members. 
Both the Mid-Columbia summer and the Tehachapi Pass winter studies produced lower average sensitivities when compared to the Tehachapi Pass summer study. The reason for the lower average sensitivities was likely caused by different factors for the two regions. For the Mid-Columbia summer study, the likely reason was the fact that more variable, large-scale flows dominate in Washington-Oregon compared to Tehachapi Pass. For the Tehachapi Pass winter studies, there was a noted lack of ensemble spread likely due to the method used to generate ensemble perturbations. The lack of spread in both the metric variable (80-m wind speed) and initial condition (IC) variables was a significant factor that affected the interpretation of the Tehachapi winter simulation experiments.

The forecast sensitivities for the Mid-Columbia Basin summer study showed that some IC variables had a low impact on the forecast. Other IC variables produced very localized and high sensitivity areas in $80-\mathrm{m}$ wind speed forecast at one of the target locations. This result was quite different from the Tehachapi Pass summer study which found well-defined, localized patterns of high sensitivity for a number of prior state variables.

The most consistently sensitive variables for the Mid-Columbia Basin forecast targets were: (1) 80-m wind speed, (2) 10-m to 80-m wind shear, and (3) 2-m to 80-m vertical temperature gradient. These variables showed regions of high sensitivity and explained variance extending from the Columbia Gorge along and just south of the Mid-Columbia Basin stretching into far eastern Washington State. Areas within the Mid-Columbia Basin showed correlations to all three sites. This result suggested that a relatively small number of observations in this area would have a beneficial impact on the 80-m wind speed forecast at all three target locations. The results of this study indicate that both the seasonal weather regimes and exact implementation of the ESA-MOOA method have a dramatic influence on using the results to guide the design of sensor networks intended to improve forecast performance.

An important finding of the Mid-Columbia MOOA was that it is necessary to use all three identified variables/locations in order to achieve consistent value for the ramp event cases. This result implies that increasing the number of variables when using the MOOA does add value to the analyses. The results demonstrate that the ESA-MOOA method can produce physically consistent forecast sensitivity results for mesoscale flows and short time scales. This information can then be used to provide specific and physically reasonable guidance for the design of sensor networks intended to improve the performance of forecasts for specific variables (forecast metrics) and locations (forecast target areas).

In Task 1 of Phase III, three sets of data denial and assimilation experiments were performed using historical data in order to validate the ESA approach for the Mid-Columbia Basin region (Zack at al., 2011a). The impact of met tower observations was examined for locations for which forecasts were predicted to be sensitive to the atmospheric state by the ESA-MOOA method developed by Zack et al. (2010a, b, and c). The objective of the data denial and assimilation experiments was to determine if the 80-m wind forecasts for three target locations were more sensitive to actual met tower observations in highly sensitive areas versus areas of low sensitivity with the inference being that meteorological observations within the highly sensitive areas would lead to better forecast performance.

The first set of experiments was performed for the warm season, testing the impact of assimilating data at high and low sensitive locations compared with assimilating all available met tower data regardless of location. The results indicated that adding met tower observations significantly improved the initial state of the atmosphere at the target locations, but the experiments also indicated that imbalances were introduced from data assimilation causing an increase in error during the first 2 to 3 hours of the forecast (Figure A1 and A2). 
The second set of experiments was performed for the cool season using the same type of sensitivity experiments as done for the warm season. The analysis of the cool season results was hindered by the fact that met tower observations for the target locations were not available for this time period so proxy sites were used for verification.

The results from the cool season experiments differed somewhat from location to location, making it difficult to draw a general conclusion. Part of the reason for this difference was due to the fact that off-site proxy met towers had to be used for verification, instead of on-site observations. Even with the difficulties caused by not having target location met towers, it is reasonable to infer that assimilating met tower observations does have a direct impact on the forecasts by improving the initial model state and also forecast performance for the first 3 hours (Figure A3 and A4).

The third set of four warm season experiments was designed to learn more about the impact of the data assimilation scheme used to assimilate the met tower observations into the model's initial state. These experiments all involved modifications of the warm season experiment that assimilated all available met tower data. The divergence constraint, IAU and ADAS experiments did not improve the forecasts (Figure A5). However, the additional experiment using a different covariance structure provided further insight into how to construct a real-time data assimilation system in order to realize the full benefits from observations in highly sensitive locations as predicted by the ESA technique.

The results from the modified covariance experiment indicate that the data assimilation system used in the experiment cannot properly estimate the spatial background covariance with the same detail as ESA. The lower forecast MAE of the modified covariance runs suggests there is a direct relationship between how the assimilation system determines the impact that an observation will have on the initial field and the forecast performance through better estimates in spatial covariance structure. Therefore, a technique that can more accurately assess the background covariance structure similar to the ESA technique, but that is more computationally efficient for real-time forecasting applications, will be needed to validate the sensitivity structure produced.

The overall results of the study indicate that the initial model state and the first forecast hour are improved when observed tower data are assimilated. For the warm season runs this impact was most pronounced closer to the initialization time, while for the cool season the improvement in the forecast was visible in the first $0-3$ hours depending on the proxy verification location. This indicates that the forecasted atmospheric flow is highly uncorrelated with the impact of observations from one location to another location. After the third hour, the impact of the assimilated observations is minimal on the forecasts. However, a slight improvement in the forecasts with all of the met towers assimilated can be seen as far out as hour 16 in some of the forecasts. Due to the lack of observations during the cool season at the target site, it can only be implied that results presented here are relevant to the actual target locations. Results also indicate that the impact of observations were sensitive to seasonal flow, observation location, and the data assimilation scheme.

Even though there are differences between the cool and warm season results, the cool season results are consistent with the warm season conclusions: (1) adding met tower observations significantly improved the values of near surface wind speed in the initial model state of the atmosphere at the target locations and (2) imbalances were introduced into the model causing an increase in error during the spin-up time.

The lower forecast MAE of the modified covariance runs suggests that a technique which can better estimate background error covariance structures similar to the ESA technique will be needed to validate the sensitivity structure produced. However, the technique will need to be computationally efficient enough for real-time applications. Computationally efficient techniques, such as a hybrid-3DVAR assimilation method, that can address the need for better estimates of background error covariance 
structures are under development for future use. The hybrid method estimates the background error covariance by using a smaller and lower resolution ensemble that is similar to the ESA technique but requires less computational resources. This technique links the spread from the ensemble to the covariance structure of a single high-resolution 3DVAR assimilation system as described by Wang et al. (2008a, b).

In addition, bias correction techniques such as the Mass et al. (2006) method should be examined for future applications where model and assimilation biases are noticeably present. Bias correction techniques are computationally efficient and only require a simple bias correction applied directly to the observations before assimilation. This technique can be used independent of the assimilation method or numerical model used. It is particularly valuable in regions where a numerical bias is prominent as in the experiments for the Mid-Columbia River Basin. Therefore, the new hybrid assimilation technique coupled with an observational bias correction method offers the potential for short-term forecast improvement in future research projects.

In order to test ESA strategies for future instrumentation deployment, a set of OSSEs were performed for a 9-day period for both cool season and warm season periods (Zack et al. 2011b) in Task 2. The control experiments assimilated synthetic rawinsonde and surface data from the nature runs. The remaining experiments tested various possible deployment scenarios involving $80-\mathrm{m}$ met towers that measure temperature, pressure, dew point temperature, wind speed, and wind direction only at one level, and sodars that measure only wind between about 30 and $200 \mathrm{~m}$ above ground level. Further research is warranted to determine the best deployment strategy on a cost-benefit basis considering the number, types, and locations of future instrumentation.

The warm season results suggest that assimilating a single observation at the target location improved the initial conditions, but the forecast was only improved for the first hour (Figure A6). The addition of a modest number of sodars (ten or less) in locations suggested by the ESA analyses reduced the MAE of the $80-\mathrm{m}$ wind speed from $10-20 \%$ through the first four to five hours of the forecasts. The use of sodar data, which has wind information over multiple vertical levels surrounding wind turbine hub heights, had a greater positive impact than meteorological tower data at a single level, despite the use of thermodynamic variables from tower data.

For the cool season, none of the OSSEs produced a significant improvement for the first three forecast hours, although there was some improvement in the fourth and fifth hours (Figure A7). It seems likely that it is more difficult to improve forecasts in the cool season when synoptic influences are greater and conventional data captures a greater portion of the atmospheric circulations that impact wind speeds in the Mid-Columbia Basin.

Task 2 results indicated that the use of met tower data in locations with a high sensitivity for BPA sites could improve the short-term forecast, if the data assimilation system is properly configured to maximize the value provided by the observations. This finding is consistent with the Task 3 results improvements in the forecast for the first few hours may be possible with a modest number of observations in high sensitivity areas, but more work is needed to find and tune the best assimilation procedure for this particular geographic area and instrumentation types.

\section{Publications}


Ancell, B. and G. J. Hakim, 2007: Comparing adjoint- and ensemble-sensitivity analysis with applications to observation targeting. Mon. Wea. Rev., 135, 4117-4134.

Torn, R. D., and G. J. Hakim, 2008: Ensemble-based sensitivity analysis. Mon. Wea. Rev., 136, 663-677.

Wang, X., D. M. Barker, C. Snyder, and T. M. Hamill, 2008a: A Hybrid ETKF-3DVAR Data Assimilation Scheme for the WRF Model. Part I: Observing System Simulation Experiment. Mon. Wea. Rev., 136, 5116-5131.

Wang, X., D. M. Barker, C. Snyder, and T. M. Hamill, 2008b: A Hybrid ETKF-3DVAR Data Assimilation Scheme for the WRF Model. Part II: Real Observation Experiments. Mon. Wea. Rev., 136, 5132-5147.

Zack, J., E. Natenberg, S. Young, J. Manobianco, and C. Kamath, 2010a: Application of ensemble sensitivity analysis to observation targeting for short-term wind speed forecasting, Technical Report LLNL-TR-424442, 32 pp., Lawrence Livermore National Laboratory, Livermore, CA.

Zack, J., E. Natenberg, S. Young, G. Van Knowe, K. Waight, J. Manobianco, and C. Kamath, 2010b: Application of ensemble sensitivity analysis to observation targeting for short-term wind speed forecasting in the Washington - Oregon Region, Technical Report LLNL-TR 458086, 65 pp., Lawrence Livermore National Laboratory, Livermore, CA.

Zack, J., E. Natenberg, S. Young, G. Van Knowe, K. Waight, J. Manobianco, and C. Kamath, 2010c: Application of ensemble sensitivity analysis to observation targeting for short-term wind speed forecasting in the Tehachapi Region winter season, Technical Report LLNL-TR 460956, 57 pp., Lawrence Livermore National Laboratory, Livermore, CA.

Zack, J., E. Natenberg, G. V. Knowe, J. Manobianco, K. Waight, D. Hanley, and C. Kamath, 2011a: Use of Data Denial Experiments to Evaluate ESA Forecast Sensitivity Patterns, Technical Report LLNL-TR-499166, 33 pp., Lawrence Livermore National Laboratory, Livermore, CA.

Zack, J., E. Natenberg, G. V. Knowe, J. Manobianco, K. Waight, D. Hanley, and C. Kamath, 2011b: Observing System Simulation Experiments (OSSEs) for the Mid-Columbia Basin, Technical Report LLNL-TR-499162, 17 pp., Lawrence Livermore National Laboratory, Livermore, CA.

\section{Acknowledgments}

This work was performed under the auspices of the U.S. Department of Energy by Lawrence Livermore National Laboratory under Contract DEAC52-07NA27344. The work of the authors from AWS Truepower was performed under subcontract B591225 from Lawrence Livermore National Laboratory.

\section{$5 \quad$ Appendix A: Figures}




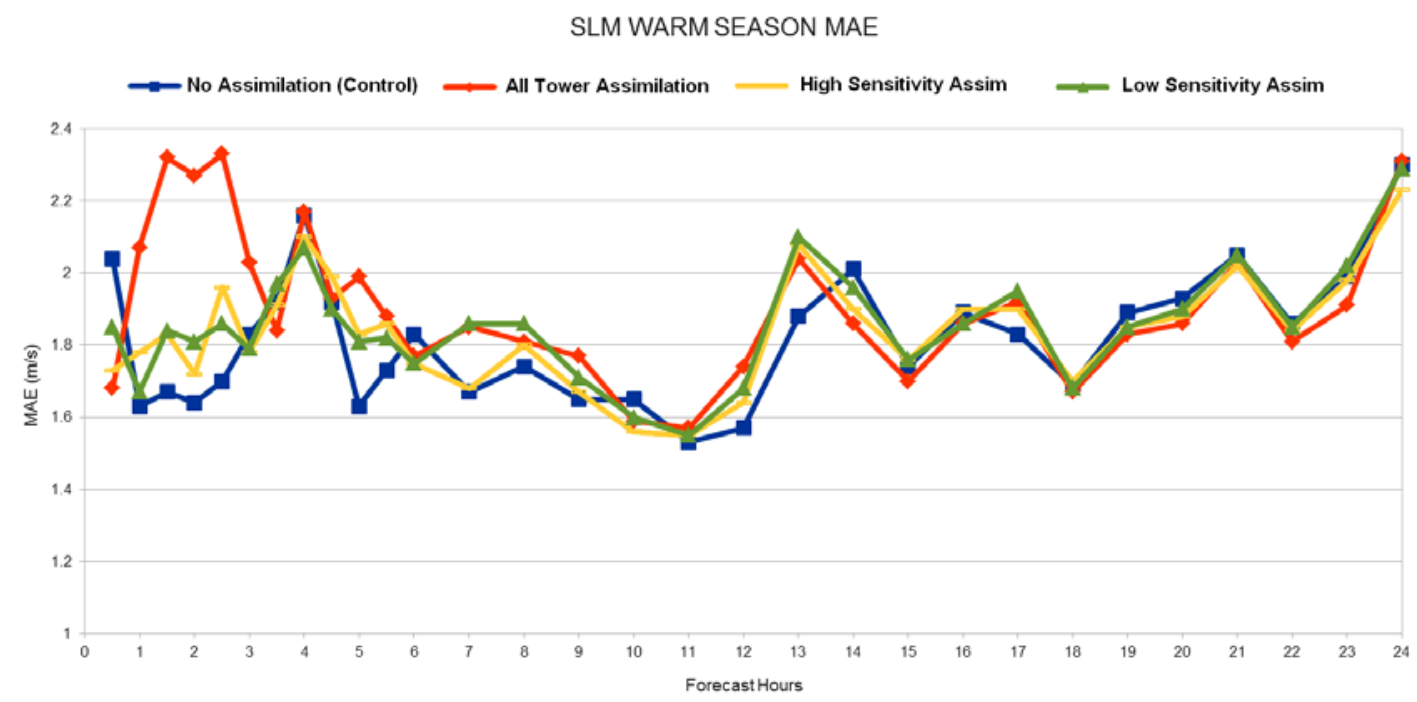

Figure A1. Mean absolute error (MAE) as a function of look-ahead time for twice per day (0000 and 1200 UTC initialization times) NWP forecasts of 80-m wind speed $\left(\mathrm{ms}^{-1}\right)$ for the SLM (Stateline) wind farm for the warm season (1 May - 20 June 2007) for the control run without met tower data assimilation (blue line), the all six Bonneville Power Administration (BPA) meteorological tower data assimilation run (red-orange line), assimilation of a high sensitivity observation point (yellow line), and the assimilation of a low sensitivity observation point (green line).

SLM WARM SEASON BIAS

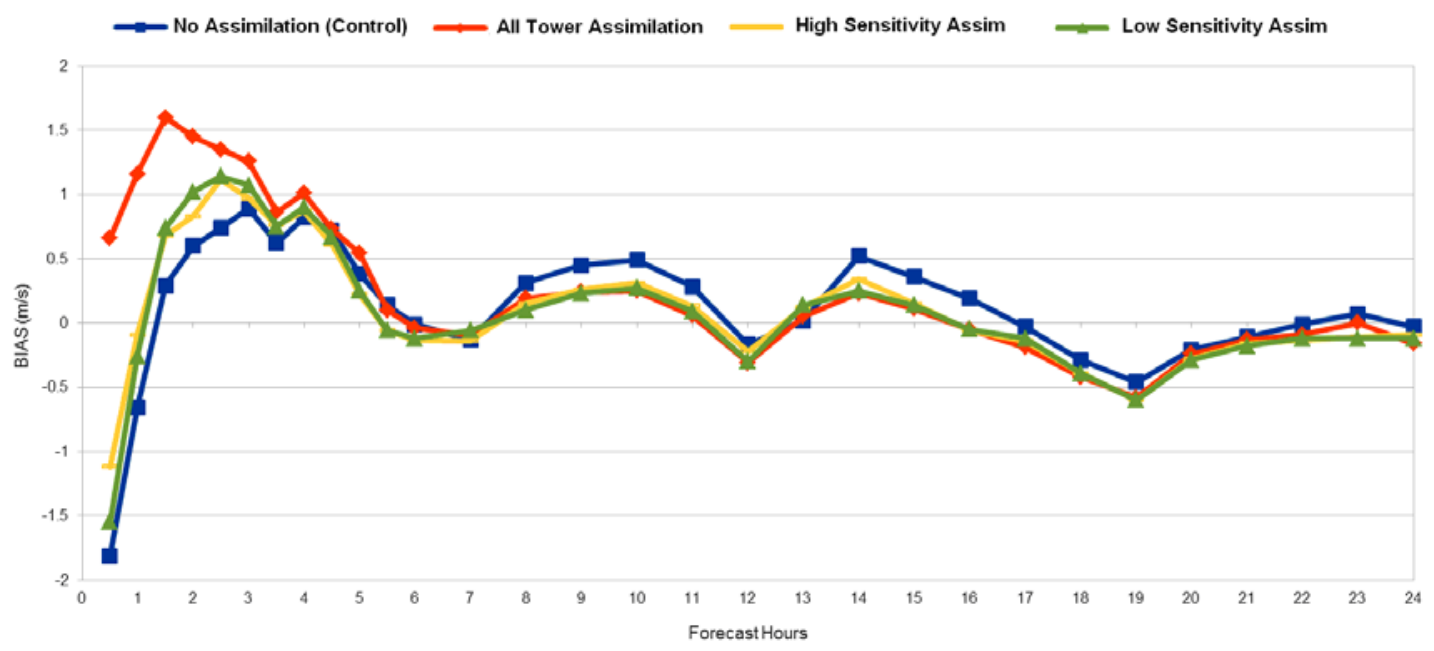

Figure A2. Bias (Mean Error) as a function of look-ahead time for twice per day (0000 and

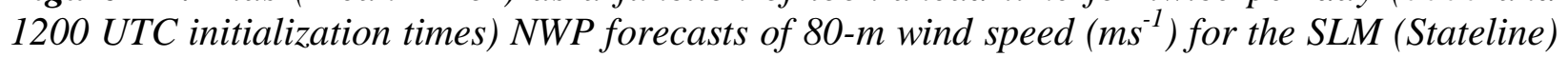
wind farm for the warm season (1 May - 20 June 2007) for the control run without met tower data assimilation (blue line), the all six Bonneville Power Administration (BPA) meteorological tower data assimilation run (red-orange line), assimilation of a high sensitivity observation point (yellow line), and the assimilation of a low sensitivity observation point (green line). 
VNM COOL SEASON MAE

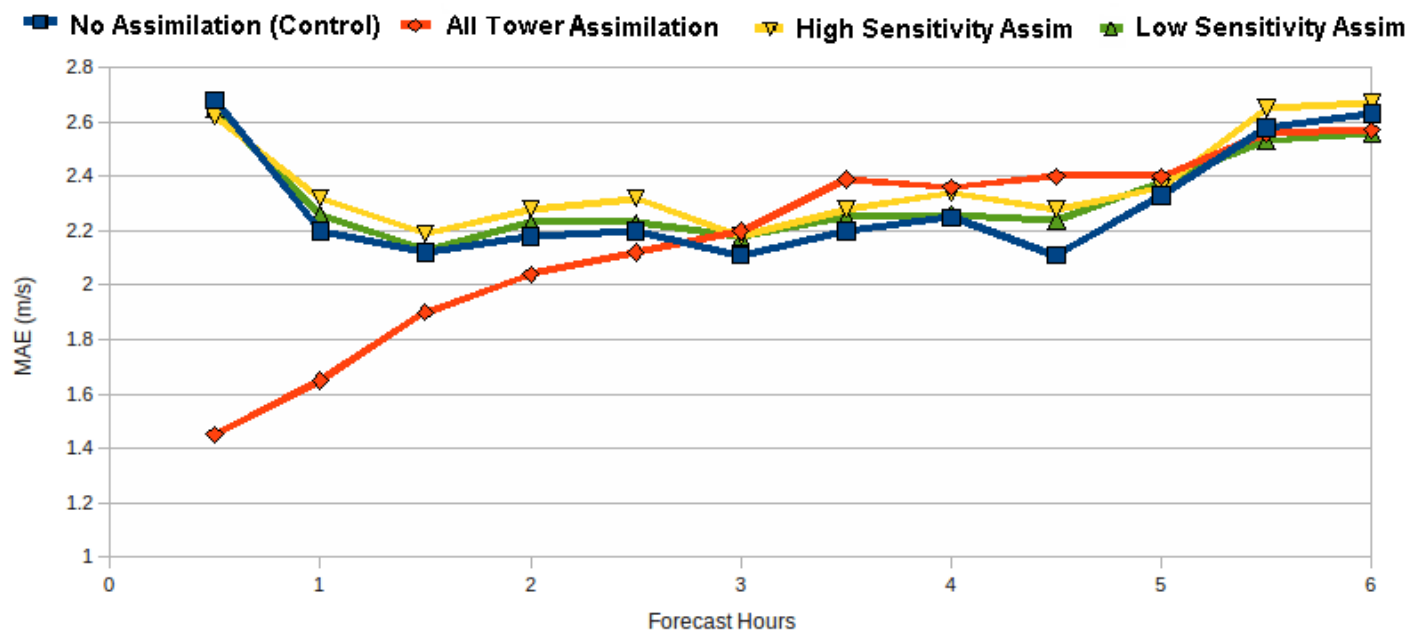

Figure A3. Same as Figure A1 except for 62-m wind speed $\left(\mathrm{ms}^{-1}\right)$ for the VNM (Vansycle) met tower for the cool season (1 January - 20 February 2010).

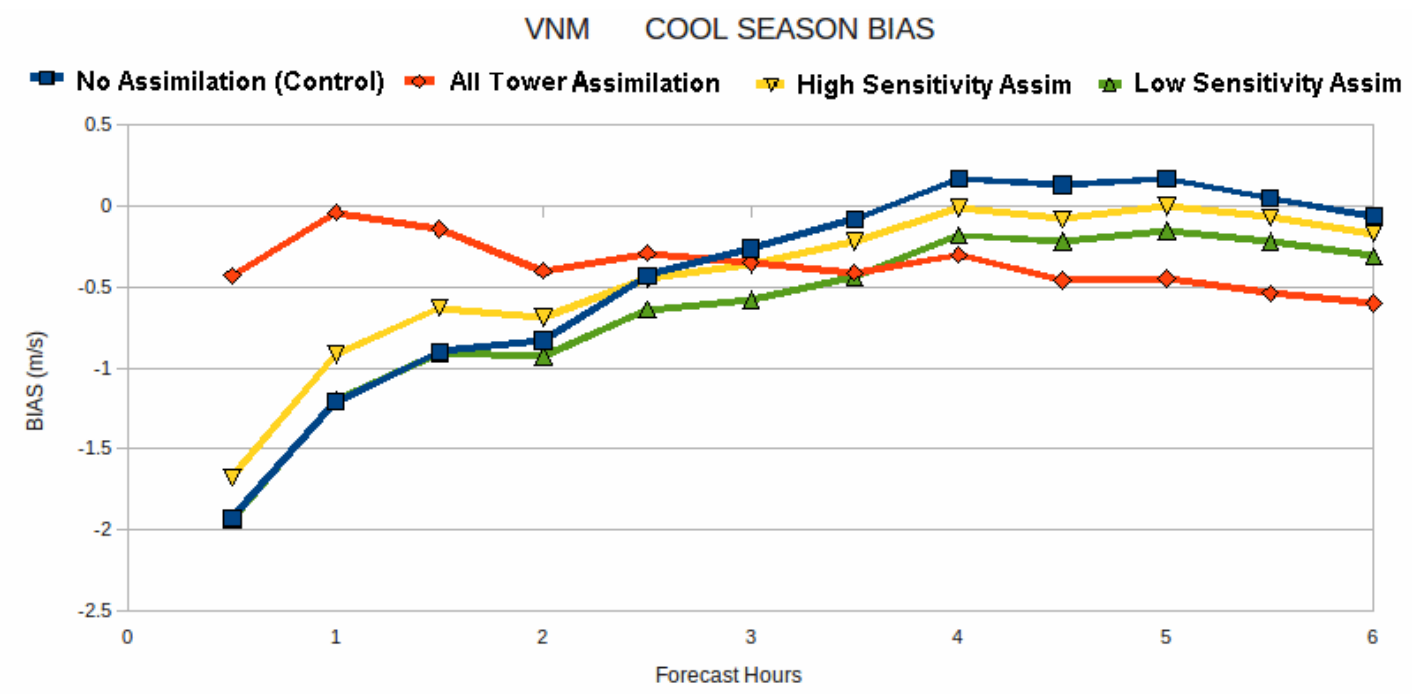

Figure A4. Same as Figure A2 except for 62-m wind speed $\left(\mathrm{ms}^{-1}\right)$ for the VNM (Vansycle) met tower for the cool season (1 January - 20 February 2010). 


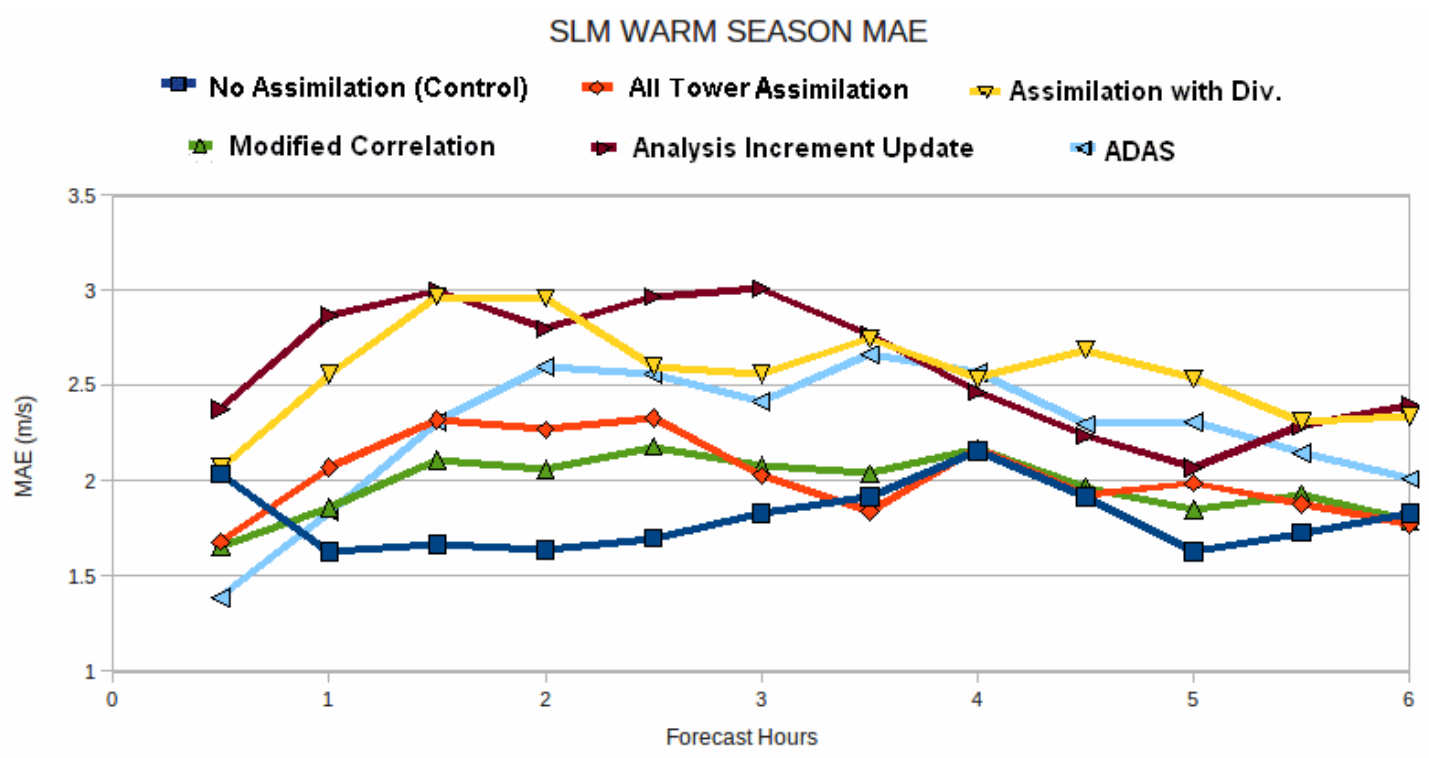

Figure A5. Mean absolute error (MAE) as a function of look-ahead time for twice per day (0000 and 1200 UTC initialization times) NWP forecasts of 80-m wind speed $\left(\mathrm{ms}^{-1}\right)$ for the SLM (Stateline) wind farm for the warm season (1 May - 20 June 2007) for the control run without met tower data assimilation (dark blue line), the all six Bonneville Power Administration (BPA) meteorological tower data assimilation run (red-orange line), assimilation with the divergent constraint (yellow line), the assimilation with a modified correlation function (green line), the assimilation using IAU (brown line), and the assimilation using ADAS (light blue line) using observations from the six BPA meteorological towers. 


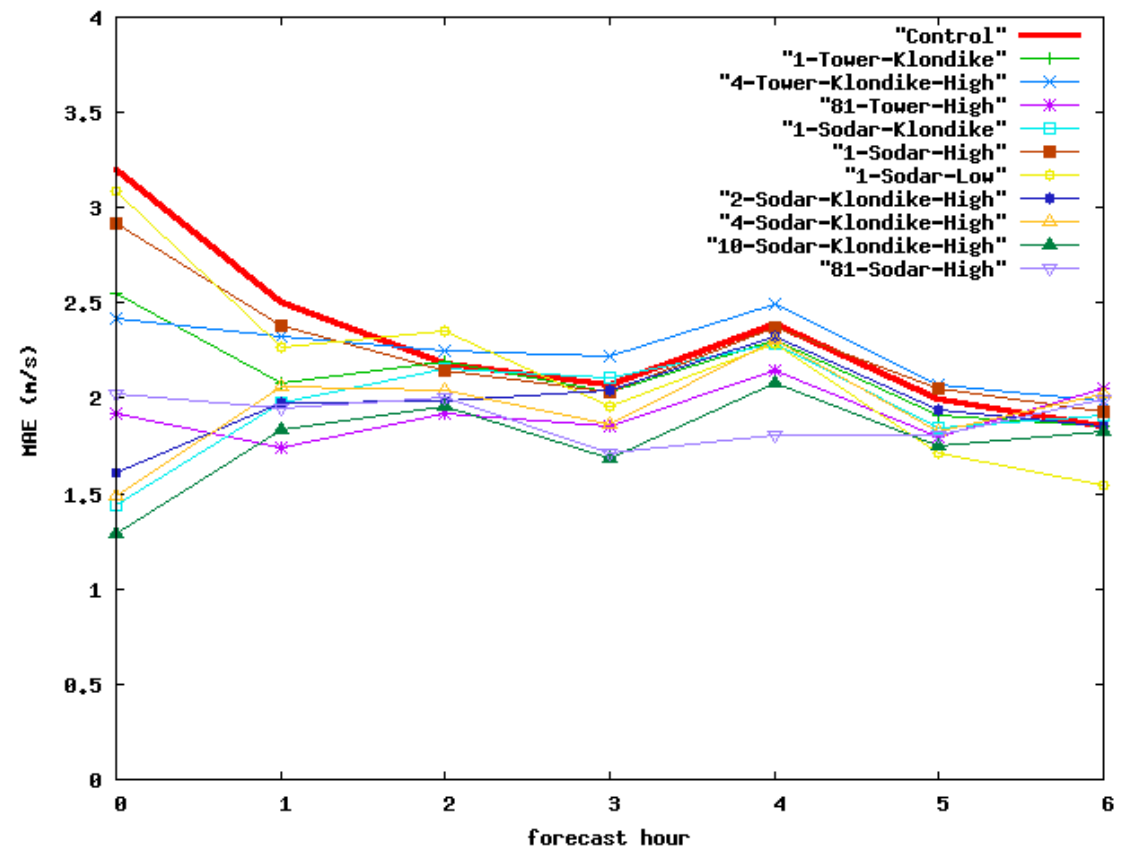

Figure A6. Mean absolute error (MAE) of 80-m wind speed $\left(\mathrm{ms}^{-1}\right)$ at Klondike for all of the warm season (May 2007) experiments.

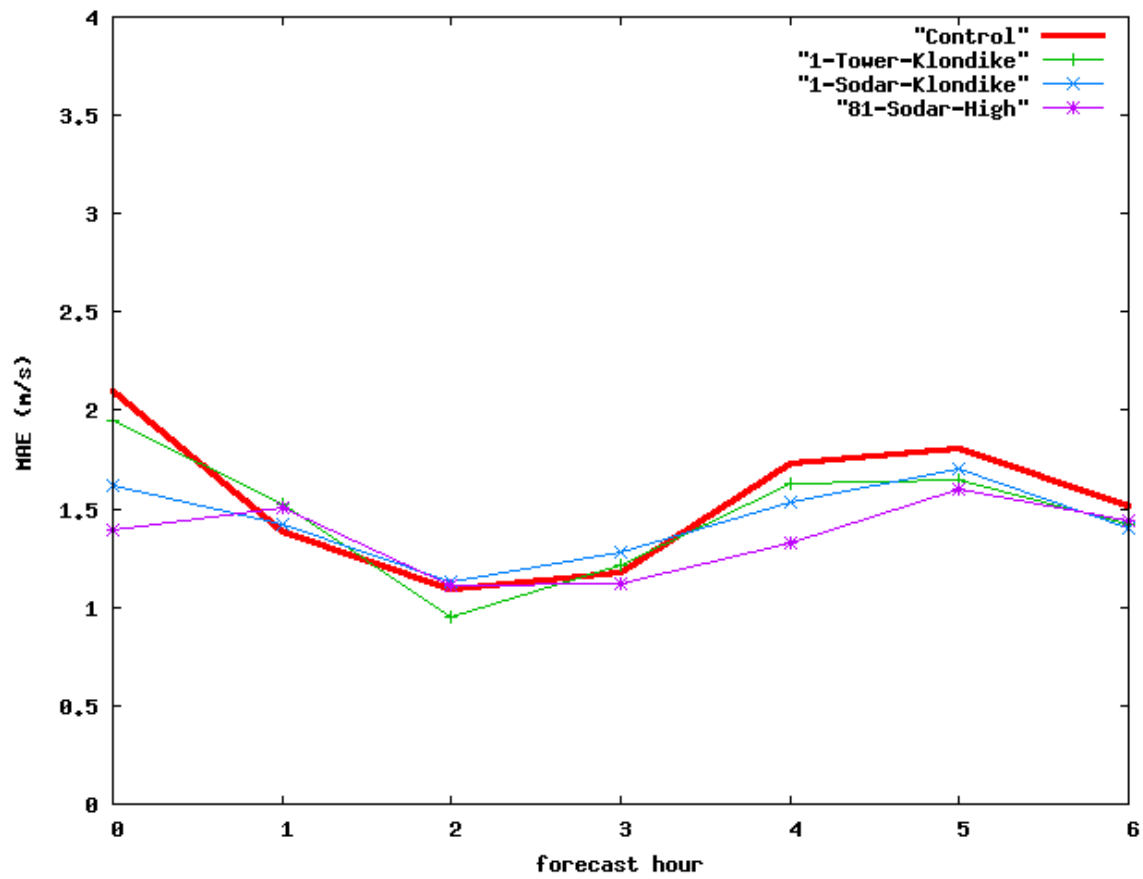

Figure A7. Mean absolute errors (MAE) of 80-m wind speed at Klondike for all of the cool season (January 2010) experiments. 
